\title{
MINOR DISCOMFORTS AMONG PREGNANT WOMEN ATTENDING IN BENI- SWEIF UNIVERSITY HOSPITAL
}

\author{
Prof. Dr. Adel Al-Wehedy Ibrahim ${ }^{1}$, Laila Awadin Ali Hassan ${ }^{2}$ \\ Mansoura Faculty of Medicine, Public Heath Department, Occupational Medicine ${ }^{1}$ \\ Lecturer of Community Health Nursing, Faculty, Beni-Sweif University ${ }^{2}$
}

\begin{abstract}
Most pregnant women suffer from minor discomforts during their pregnancy period. These minor discomforts are due to hormonal change. The common of minor discomforts are nausea and vomiting ,fatigue ,constipation ,heart burn, backache ,Dyspnea, leg cramps varicose vein, insomnia, urerinary frequency, and leucorrhea.

Aim: The present study aimed to explore the magnitude and types of minor discomforts among pregnant women attending Beni-Sweif University Hospital. A sample of 90 pregnant women selected from those attending in the antenatal clinic of Beni-Sweif University Hospital. Asructureit interview questionnaire was developed and used for data collection to assess women's socio-demographic and obstetric characteristics, and pregnancy related to problems .

Based of data collection of the current study It can be concluded that the majority of the pregnant women complained from minor discomfort during pregnancy period these were; vaginal discharge,,frequenancy of urinantion, back ache ,nausea ,heart burn ,drowsiness difficult of breathing ,constipation heavy breast and muscles spasm. Recommendations Awareness raising programs must be conducted regarding importance of antenatal care to improve mothers' knowledge regarding minor discomfort . In- services training to all nurses and health care provider at maternal health services to up date their knowledge ,increase their ability to care for pregnant mother with discomfort and instruct them to avoid their unhealthy lifestyle behaviors.
\end{abstract}

\section{Introduction}

Pregnancy is a normal process that results in a series of both physiological and psychosocial changes in the women. Some of these are temporary changes that occur only during pregnancy (Lowdermilk \& Perry, 2007). Most pregnant women suffer from minor discomforts during their pregnancy period. These minor discomforts are due to hormonal change and metabolic change (Amasha \& Heeba , 2013). Symptoms of discomforts are different from women to women through the different months of pregnancy.
The prevalence of minor discomforts is varying according to its type. Nausea and vomiting (morning sickness) are of the most common discomforts of the early pregnancy. Nausea and vomiting appear early in the first trimester (6 to 8 weeks) and subside by the end of 12 weeks of pregnancy's improve nausea and vomiting the pregnant women should be taken a piece of dry toast before getting up, small meals of high quality (protein ) food. According to Avosor and Keskin 2012, fainting occurring in the first and second trimesters due to vasodilatation occurring under the influence of progesterone increasing of blood 
volume. To improve fainting the ladies should be measuring the blood pressure, avoiding hard work, rest increasing fluids and taking balanced diet .

Fatigue occurs primary during the first and third trimester of pregnancy. .In the first trimesters fatigue is usually related to physiological and hormonal changes. During the third trimester fatigue is usually related to physical discomforts and inability to sleeping To improve fatigue, the mother is advised to eat healthy food, taking naps during the day, increasing time exercise, and practicing relaxation techniques ( Rice, 2006). According to Rosy , ( 20 10), hormonal change may cause headache during pregnancy especially during the first trimester. To relive from headache the ladies are advised to take rest, proper nutrition and adequate fluid intake which may help alleviate headache, symptoms. In severe headache the ladies go to the doctor to take. medicine. Heart burn is common during pregnancy particularly during the last trimester, it is described painful retrostenal burning sensation.

In some studies the prevalence of heart burns has been found to increase from $22 \%$ in the first trimester to $39 \%$ in the second trimester and $60 \%$ to $70 \%$ in the third trimester women are advised to avoid spicy food, increase milk and milk productions and warm fluid (Archer,2oo6). Backache more than two third of the pregnant women experience back pain and almost one fifth experience pelvic pain .The pain increases with advancing pregnancy and interferes with work daily activities and sleep. Pennick \&Young ,(2007), reported that backache improves by exercise program and postural education given to the women as early in the pregnancy as possible may which prevent back pain or decrease pain. Many women experience leg cramps in the second trimester of pregnancy. .Both calcium and sodium chloride appear to help reduce leg cramps in the pregnancy(Jewell\& Young, 2000). Dyspnea or shortness of breath occure in $60 \%$ of pregnant women. Dyspnea may occurs during the first trimester because of the progesterone. During the later half of pregnancy these symptoms result from the pressure of the uterus pushing upward on the diaphragm . It may be relieved by advising the women to sleep on additional pillows. Maintains good posture decreases anxiety as well as taking deep breathing (Klossner \& Hatfied2010).

Pregnancy is presumed to be a major contributory factor in the increased incidence of varicose vein in the women which can in turn lead to venous insuffiency and leg edema. Most common symptoms of varicose vein and edema are substantial pain experienced as well as night cramps numbness, tingling and the legs may feel heavy, varicose may develop in up to $40 \%$ of pregnant women. Varicose vein often improves three to four months following birth and edema generally reduces soon after birth (Bamigboye\&Hofmer, 2006).

Insomnia in later weeks of pregnancy may have a variety of causes including physical discomfort and stress. To relieving from insomnia, the pregnant women should be taking warm bathing before bed time and pillow in inviting way that promotes rest. (Orsohan, 2008). Constipation is a common problem in late of pregnancy circulating progesterone may be a causes of showering gastroinstinal movement in mild and later pregnancy .Constipation often improves by intake of dietary supplements 
in the form of bran, if the problem fails to resolve ,stimulant laxative are likely to prove more effective. (Iewel \& Youn, 2000).

In early pregnancy, women experience urinary frequency from the growing uterus compressing the bladder. Pregnant women often are fatigue a because of nocturia and increased metabolic requirement. One cause of frequent urination in the first trimester is the increasing blood all diminishes during second trimester, only to reappear in the their volume and increasing glomerular-filtration rates . According to lowdermilk et al. ,(2010), high level of estrogen in pregnancy results in marked shedding of superficial mucosal cell in vaginal discharge,(Leucorrhea) some relieving measures are the avoidance of tight clothing the mother should be wear cotton underwear, washing with plain water twice a day and medicine as doctors order. During pregnancy the ladies refuse taking any medicine to relieve minor discomforts because any drugs may affect on the fetal development. Therefore, most women in development countries return to their traditional or cultural practices. These women adhere to traditional practices aimed to restoring their health and preventing themselves and their babies from developing illness (Ngenda et al., 2003). Role of the community health nurse: The nurse can help pregnancy appositive experience by providing information, suggestion, emotional support and ongoing reassurance to the mother and her partner. So, the nurse can focus on special needs of the pregnant adolescents to promote optimal maternalchild health.
Aim of the study: This study was carried out to explore the magnitude and types of minor discomforts among pregnant women attending Beni-Sweif University Hospital.

\section{Technical Design:}

Across sectional design was used

\section{Sample}

A sample of 90 pregnant women selected randomly from those attending anti natal care clinic of Beni Sweif University Hospital, were chosen randomly at visit by the reacercher.

\section{Sample size}

To calculate the sample size, a calculator was used. Assuming that back pain prevalence in pregnant ladies varies from $40-60 \%$ (Pennick \&Yourg,2007). At 95\% significance level and $80 \%$ powers of the study, the calculated sample size was $70 \%$, adding $20 \%$, for improving collected data. So, the actual sample size was 90 women.

\section{Tool of data collection:}

A structured interview questionnaire was developed by the researchers and tested to collect data related to minor discomforts among pregnant women attending in Beni- Sweif University Hospital. It was written in Arabic language to facilitate communication with pregnant women. The structured interview questionnaire included the following:

- Demographic data, such as, age, address, education and occupation .

- Obstetrical data, such as data of last menstrual period, duration of pregnancy -number of previous pregnancies

- Questions related to minor discomforts among pregnant women such as, nausea, vomiting faintness, fatigue, 
headache ,heart burn, back-ache, dyspnea ,edema ,insomnia and anxiety ,breast change ,varicosevein and leg cramps, and leucorrhea.

Administration design: After clarifying the aim of the study, approval to carry out this study was obtained from the concerned authorities (Hospital Director).

- Operational Design : This design included the preparatory phase description, the pilot study, and filed work.

- Preparatory phase: Based on previous introduction and researches in journals, magazine and computer search, the tools of the data collection were developed .

- Pilot study : After preparing the tools a study was tested on 10 pregnant women at the anti natal clinic in Beni-Sweif University Hospital. The questionnaire were clear and relevant and few words and items were modified.

- Field work: The data collection started from 6/2016 till 9/2016

.Data were collected through interview pregnant women during flow up visits $10 \mathrm{AM}$ to $1 \mathrm{PM}$ in the anti natal clinic in university hospital .
Ethical consideration :An approval was obtained from pregnant women to participate in the study. The researchers introduced them solve the aim of the study was illustrated to them, they were assure that their participation is voluntary and Wright to withdraw from the study at any time without given any reason

\section{Statistical Design:}

Collected data were coded, computed and statistically analyzed using the statistical package for social sciences version 16.0. of percentages $\chi^{2}$ (Chi square) test was used. The differences was were presented as frequencies and considered significant at $\mathrm{P} \leq 0.05$.

\section{Results:}

Table (1) shows the characteristics of the studied women (90 pregnant ladies). The age of 90 studied pregnant ladies ranges from 18.0 to 45.0 years with $30.40 \pm 7.26$ years. Those having age $20-<30$ are $42.8 \%$ and from $30-<40$ are $37.8 \%$. The percentages of rural and urban women in the studied sample $52.2 \%, 47.8 \%$ of them respectively less education, while secondary and university education are $38.2 \%$ and $42.2 \%$ respectively and $37.8 \%$ of them are working. As regards obstetric history, almost of them has no previous pregnancies and they are gravid, a while $27.8 \%$ are $2^{\text {nd }}$ gravid , $33.3 \%$ are $3^{\text {rd }}$ gravid and $5.6 \%$ are $4^{\text {th }}$ gravid. The percentages of those in the $1^{\text {st }}, 2^{\text {nd }}$ and $3^{\text {rd }}$ trimesters are $21.1 \%, 38.9 \%$ and $40.0 \%$ respectively. 
Table (1): Characteristics of the Studied Women ( $n=90)$.

\begin{tabular}{|c|c|c|c|}
\hline Characteristics & Items & No & $\%$ \\
\hline \multicolumn{4}{|c|}{ Demographic characteristics } \\
\hline \multirow[t]{5}{*}{ Age (years) } & $<20$ & 7 & 7.8 \\
\hline & $20-$ & 38 & 42.8 \\
\hline & $30-$ & 34 & 37.8 \\
\hline & $40+$ & 11 & 12.2 \\
\hline & Range: $18.0-45.0$ & \multicolumn{2}{|c|}{ Mean $\pm \mathrm{SD}=30.40 \pm 7.26$} \\
\hline \multirow[t]{2}{*}{ Residence } & Rural & 47 & 52.2 \\
\hline & Urban & 43 & 47.8 \\
\hline \multirow[t]{5}{*}{ Education } & Illiterate & 1 & 1.1 \\
\hline & Primary & 8 & 8.9 \\
\hline & Preparatory & 8 & 8.9 \\
\hline & Secondary & 35 & 38.2 \\
\hline & University & 38 & 42.2 \\
\hline \multirow[t]{2}{*}{ Work } & Working & 34 & 37.8 \\
\hline & Not working & 56 & 62.2 \\
\hline \multicolumn{4}{|c|}{ Obstetric characteristics } \\
\hline \multirow{4}{*}{$\begin{array}{l}\text { No of Previous } \\
\text { pregnancies }\end{array}$} & 0 & 30 & 33.3 \\
\hline & 1 & 25 & 27.8 \\
\hline & 2 & 30 & 33.3 \\
\hline & 3 & 5 & 5.6 \\
\hline \multirow{4}{*}{$\begin{array}{l}\text { Order of the current } \\
\text { pregnancy }\end{array}$} & 1 & 30 & 33.3 \\
\hline & 2 & 25 & 27.8 \\
\hline & 3 & 30 & 33.2 \\
\hline & 4 & 5 & 5.6 \\
\hline \multirow{3}{*}{$\begin{array}{l}\text { Current Pregnancy } \\
\text { period }\end{array}$} & $1^{\text {st }}$ trimester & 19 & 21.1 \\
\hline & $2^{\text {nd }}$ trimester & 35 & 38.9 \\
\hline & $3^{\text {rd }}$ trimester & 36 & 40.0 \\
\hline
\end{tabular}

Table (2) shows the distribution of the pregnancy related problems and their relation to pregnancy duration. Suffering from nausea is recorded in $70.0 \%$ of the studied pregnant women and it is significantly higher in the $1^{\text {st }}$ trimester $94.7 \%$ than $2^{\text {nd }} 80.0 \%$ and $3^{\text {rd }}$ trimesters $47.2 \%$. Also, $45.6 \%$ of them are suffering from vomiting and it is significantly higher in the $1^{\text {st }}$ trimester. Forty percent are suffering from headache, $73.3 \%$ from acidity, $62.2 \%$ from drowsiness and $45.6 \%$ from heavy breasts with no significant difference by the period of pregnancy. Back pain is recorded in $73.3 \%$, difficult breathing $50.0 \%$, frequent urination $70.0 \%$ and constipation $40.0 \%$ with significant increase in the $3^{\text {rd }}$ trimester than first and second ones. Muscle spasm $(38.9 \%)$ and difficult sleeping $74.4 \%$ are significantly lower the $2^{\text {nd }}$ than trimester than first and third ones. While leg varicosity $30.0 \%$ and increased vaginal discharge $64.4 \%$ are significantly increase in the $3^{\text {rd }}$ trimester than $1^{\text {st }}$ and $2^{\text {nd }}$ ones. 
Adel Al-Wehedy \& Laila Awadin

Table (2) Distribution of Minor Discomforts Among Pregnant Women ( $n=90)$.

\begin{tabular}{|c|c|c|c|c|c|c|c|c|c|c|}
\hline \multirow{4}{*}{\begin{tabular}{|l|}
\multicolumn{1}{c|}{$\begin{array}{c}\text { Pregnancy } \\
\text { related problems }\end{array}$} \\
Nausea
\end{tabular}} & \multirow{4}{*}{$\begin{array}{l}\text { Items } \\
\text { Yes } \\
\text { No }\end{array}$} & \multicolumn{2}{|c|}{$\begin{array}{c}\text { Total } \\
(\mathbf{9 0})\end{array}$} & \multicolumn{2}{|c|}{$\begin{array}{c}1^{\text {st }} \text { trimester } \\
\text { (19) }\end{array}$} & \multirow{2}{*}{\multicolumn{2}{|c|}{$\begin{array}{c}2^{\text {nd }} \\
\text { trimester } \\
(35)\end{array}$}} & \multirow{2}{*}{\multicolumn{2}{|c|}{$\begin{array}{l}3^{\text {rd }} \\
\text { trimester }^{\text {rd }} \\
\text { No }\end{array}$}} & \multirow{4}{*}{$\begin{array}{l}\mathrm{X} 2 \\
\text { p-value } \\
\chi^{2}=16.097 \\
\mathrm{P} 0.000\end{array}$} \\
\hline & & \multicolumn{2}{|c|}{ No $\%$} & \multicolumn{2}{|c|}{ No $\%$} & & & & & \\
\hline & & 63 & 70.0 & 18 & 94.7 & 28 & 80.0 & 17 & 47.2 & \\
\hline & & 27 & 30.0 & 1 & 5.3 & 7 & 20.0 & 19 & 52.8 & \\
\hline Vomiting & Yes & 41 & 45.6 & 16 & 84.2 & 19 & 54.3 & 6 & 16.7 & $\chi^{2}=24.635$ \\
\hline & No & 49 & 54.4 & 3 & 15.8 & 16 & 45.7 & 30 & 83.3 & P 0.000 \\
\hline Headache & Yes & 36 & 40.0 & 10 & 52.6 & 16 & 45.7 & 10 & 27.8 & $\chi^{2}=3.980$ \\
\hline & No & 54 & 60.0 & 9 & 47.4 & 19 & 54.3 & 26 & 72.2 & P 0.137 \\
\hline Acidity & Yes & 66 & 73.3 & 13 & 68.4 & 26 & 74.3 & 27 & 75.0 & $\chi^{2}=0.302$ \\
\hline & No & 24 & 26.7 & 6 & 31.6 & 9 & 25.7 & 9 & 25.0 & P 0.860 \\
\hline Back pain & Yes & 66 & 73.3 & 8 & 42.1 & 27 & 77.1 & 31 & 86.1 & $\chi^{2}=12.740$ \\
\hline & No & 24 & 26.7 & 11 & 57.9 & 8 & 22.9 & 5 & 13.9 & P 0.002 \\
\hline Drowsiness & Yes & 56 & 62.2 & 14 & 73.7 & 17 & 48.6 & 25 & 69.4 & $\chi^{2}=4.635$ \\
\hline & No & 34 & 37.8 & 5 & 26.3 & 18 & 51.4 & 11 & 30.6 & P 0.099 \\
\hline Difficult & Yes & 45 & 50.0 & 5 & 26.3 & 17 & 48.6 & 23 & 63.9 & $\chi^{2}=7.070$ \\
\hline breathing & No & 45 & 50.0 & 14 & 73.7 & 18 & 51.4 & 13 & 36.1 & P 0.029 \\
\hline Frequent & Yes & 63 & 70.0 & 8 & 42.1 & 22 & 62.9 & 33 & 91.7 & $\chi^{2}=15.938$ \\
\hline urination & No & 27 & 30.0 & 11 & 57.9 & 13 & 37.1 & 3 & 8.3 & P 0.000 \\
\hline Constipation & Yes & 36 & 40.0 & 3 & 15.8 & 13 & 37.1 & 20 & 55.6 & $\chi^{2}=8.389$ \\
\hline & No & 54 & 60.0 & 16 & 84.2 & 22 & 62.9 & 16 & 44.4 & P 0.015 \\
\hline Muscle spasm & Yes & 35 & 38.9 & 2 & 10.5 & 19 & 54.3 & 14 & 38.9 & $\chi^{2}=9.923$ \\
\hline & No & 55 & 61.1 & 17 & 89.5 & 16 & 45.7 & 22 & 61.1 & P 0.007 \\
\hline Heavy breasts & Yes & 41 & 45.6 & 6 & 31.6 & 15 & 42.9 & 20 & 55.6 & $\chi^{2}=3.051$ \\
\hline & No & 49 & 54.4 & 13 & 68.4 & 20 & 57.1 & 16 & 44.4 & P 0.218 \\
\hline Leg varicosity & Yes & 27 & 30.0 & 2 & 10.5 & 11 & 31.4 & 14 & 38.9 & $\chi^{2}=4.820$ \\
\hline & No & 63 & 70.0 & 17 & 89.5 & 24 & 68.6 & 22 & 61.1 & P 0.090 \\
\hline Difficult & Yes & 67 & 74.4 & 17 & 89.5 & 30 & 85.7 & 20 & 55.6 & $\chi^{2}=11.344$ \\
\hline & No & 23 & 25.6 & 2 & 10.5 & 5 & 14.3 & 16 & 44.4 & P 0.003 \\
\hline Increase vaginal & Yes & 58 & 64.4 & 3 & 15.8 & 21 & 60.0 & 34 & 94.4 & $\chi^{2}=34.072$ \\
\hline & No & 32 & 35.6 & 16 & 84.2 & 14 & 40.0 & 2 & 5.6 & P 0.000 \\
\hline
\end{tabular}


Figure (1) show that the response of the studied women according to their suffering from pregnancy related problems. Most of the women consult doctors $91.1 \%$, take rest $70.0 \%$ and take fluid and home material $63.3 \%$.

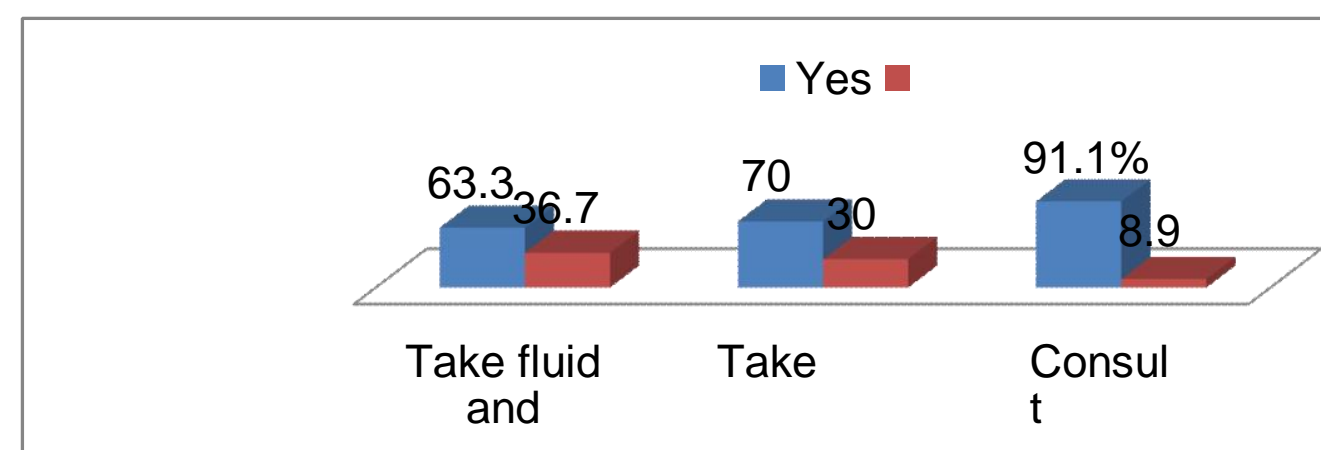

Table (3): Relationship between minor discomforts, demographic and visiting obstetric

\begin{tabular}{|c|c|c|c|c|c|c|c|}
\hline \multirow{3}{*}{ Character } & \multirow{3}{*}{ Item } & \multirow{3}{*}{ No } & \multicolumn{4}{|c|}{ Visiting doctors } & \multirow{3}{*}{$\begin{array}{l}\text { Significan } \\
\text { ce test }\end{array}$} \\
\hline & & & \multicolumn{2}{|c|}{ Yes (82) } & \multicolumn{2}{|c|}{ No $(8)$} & \\
\hline & & & No & $\%$ & No & $\%$ & \\
\hline \multirow{4}{*}{$\begin{array}{l}\text { Age group } \\
\text { (years) }\end{array}$} & $<20$ & 7 & 7 & 100.0 & 0 & 0.0 & $\chi^{2}=2.229$ \\
\hline & $20-$ & 38 & 34 & 89.5 & 4 & 10.5 & $\mathrm{P}=0.526$ \\
\hline & $30-$ & 34 & 30 & 88.2 & 4 & 11.2 & \\
\hline & $40+$ & 11 & 11 & 100.0 & 0 & 0.0 & \\
\hline \multirow[t]{2}{*}{ Residence } & Rural & 47 & 43 & 91.5 & 4 & 8.5 & $\chi^{2}=0.017$ \\
\hline & Urban & 43 & 39 & 90.7 & 4 & 9.3 & $P=0.895$ \\
\hline \multirow[t]{3}{*}{ Education } & Basic \& less & 17 & 13 & 76.5 & 4 & 23.5 & $\chi^{2}=6.120$ \\
\hline & Secondary & 35 & 34 & 97.1 & 1 & 2.9 & $P=0.047$ \\
\hline & University & 38 & 35 & 92.1 & 3 & 7.9 & \\
\hline \multirow[t]{2}{*}{ Work } & Working & 34 & 31 & 91.2 & 3 & 8.8 & $\chi^{2}=0.000$ \\
\hline & Not working & 56 & 51 & 91.1 & 5 & 8.9 & \\
\hline \multirow{4}{*}{$\begin{array}{l}\text { Previous } \\
\text { pregnancies }\end{array}$} & 0 & 30 & 28 & 93.3 & 2 & 6.7 & $\chi^{2}=1.427$ \\
\hline & 1 & 25 & 23 & 92.0 & 2 & 8.0 & $\mathrm{P}=0.699$ \\
\hline & 2 & 30 & 26 & 86.7 & 4 & 13.3 & \\
\hline & 3 & 5 & 5 & 100.0 & 0 & 0.0 & \\
\hline \multirow{3}{*}{$\begin{array}{l}\text { Current } \\
\text { pregnancy } \\
\text { period }\end{array}$} & $1^{\text {st }}$ trimester & 19 & 18 & 94.7 & 1 & 5.3 & $\chi^{2}=2.061$ \\
\hline & $2^{\text {nd }}$ trimester & 35 & 30 & 85.7 & 5 & 14.3 & $P=0.357$ \\
\hline & $3^{\text {rd }}$ trimester & 36 & 34 & 94.4 & 2 & 5.6 & \\
\hline
\end{tabular}


Table (3) shows the relationship between demographic, characteristic of the studied women and visiting doctors. No statistically significant differences of percentage visiting obstetric doctors in relation to age, residence, working, history of previous pregnancies and period of current pregnancy. However, the percentage of visiting doctors is significantly higher among secondary $97.1 \%$ and university educated $92.1 \%$ than those less educated $76.5 \%$. work in relation to more than more than three fifth of the pregnant ladies not working .Also, the current study results revealed that one third of the mother were no previous pregnancy.

\section{Discussion:}

Concerning demographic characteristics the current study findings indicated that for more than two thirds ,their age was for more than thirds age was in the age group from $20-<30$, with a mean age of $30.40 \pm 7.26$ years. As for residence, rural women under study represented more than half .Regarding their level of education ,the highest percentages representing less than two fifths were secondary education and more than two fifths were university graduates. As regards work of obstetric women, more than there fifths are not working. Considering minor discomforts among the studied pregnant women as nausea this study finding recoded the highest percentage in the first trimester representing most of them ,followed by the second trimester accounting for the majority and the least in the third trimester in less than half of them .As for vomiting, the highest percentage of the pregnant women complained from vomiting especially in the first trimester. Headache as another minor discomfort detected in this study was reported by two fifths of the pregnant women. This finding is consistent with that of Rosy ( 2007) who mentioned headache as of the causes that affected pregnant women. As regards constipation this study revealed that forty percent of the women is significant and increased in the third trimester than first \& second trimester this is consistent with (Jewell and Young, (2010) motioned that constipation is a common problem in the late pregnancy due to circulating of progesterone which may be a causes of slower gastroinstinal movement in later of pregnancy.

Concerning varicose vein and leg edema, results of the present study revealed that near one third of pregnant women are affected from varicose vain and leg edema this is an accordance with ( Magillcuerden,2011) mentioned that forty $40.0 \%)$ of the pregnant women affected from varicosese vein and leg edema.Concerning frequency of urination ,the current study finding indicated that, less than three fourths which increased in the third trimester to reach most of the women who referred frequency of to be urination due to pressure enlargement on the uterus. This finding is in accordance with Klossner and Hatfied, ( 2010) who mentioned the same cause of frequency of urination during pregnancy .

Regarding difficult of breathing results of present study revealed that half of the pregnant women complains from difficult of breathing which increased to be less than two third in the third trimester of pregnancy. This a is result from pressure of the uterus pushing upward on the diaphragm. . This finding is consistent with that Calzolan and Dalgeish mentioned as cause of Dyspnea. 
Concerning back pain, the present study result revealed that less than three fourths of the women were suffering from back pain. This finding is consistent with that of Pennick and Young, ( 2007 ) who mentioned that more than two -thirds of pregnant women were suffering from back pain.

Regarding heart burn the finding of present study indicated that less than three fourth in the study affected from heart burn this is consistent with (Archer , 2006) said to heart burn increase from $22 \%$ in the first trimester to $39 \%$ in second trimester and its increased from 60 to $70 \%$ in the third trimester

.Concerning vaginal discharge (Leycorrhea), the finding of present study indicated that less than two third of the mothers complain from vaginal discharge and significantly increase in the third trimester than first and second trimester this is in accordance with Puirman et al, (2010 mentioned that vaginal discharge is increasing in the late of pregnancy

Concerning difficult of sleeping (Insomnia), the current study result revealed that less than three fourths of the pregnant women were suffering from difficulty of sleeping due to physical discomforts, stress, nocturia or caffeine intake. This finding is consistent with (Orshan,(2008) who mentioned this cause and insomnia that occurs and increases in the third trimester . While, regarding muscle spasm, and highest in the second trimester than first and third trimesters .

Regarding distribution of the studied women according to their responses to pregnancy related problems, the findings of the present study indicated that most of the women consult the doctor less than three fourths take rest, fluid and home materials were taken by less than two thirds \& table 3 statistically .

Concerning the relationship between the characteristics of the studied ladies and visiting doctors insignificant difference of were found for doctor in relation to residence, work, history of previous pregnancies, and the current pregnancy period. On the other hand, the majority of the women visiting the doctor were significantly higher and mostly university educated than those were less education representing more than three quarters of the study sample ( table3) .

In Egyptian cultures there are harmless and harmful traditions and beliefs used by pregnant women to relieve common minor discomforts during pregnancy.

\section{Conclusion}

Based on the findings of the current study, it can be concluded that the majority of the pregnant women complain from minor discomforts during pregnancy period, these were, vaginal discharge, frequeancy of urination ,backache, nausea ,heart burn ,drowsiness, difficult of breathing , constipation heavy breast and muscle spasm.

\section{Recommendations}

In service training to all nurses and health care provides at maternal health services to update their knowledge,

,increase their ability to care for pregnant mothers with minor discomforts and instruct them to avoid their unhealthy lifestyle behaviors. 


\section{References}

- Amasha, H.,\& Heeba, M. ( 2013 ) : Maternal awareness of pregnancy normal and abnormal signs : Exploratory Descriptive study , Department of Obstetric and Gynecological Nursing, Faculty of Nursing , Port Said University, Egypt. IOS Journal of Nursing and Health Sciences (IOSR-JNHS) 2( 5Nov. De) : 39-45 available at www.iosejournals.org.

-Archer,C. (2006): How to achieve ahealthy of pregnancy. Retrieved at http//ezinearticles.com./ ?How- to Achieve-A-Healthy-pregnancy\&id $=365130$

- Bamigbye, A.A\&.Hofmeyr, GJ. (2006): Intervention for leg odema and varicosities in pregnancy. What evidence? Eur J Obstet Gynecol Reprod Biol. Nov./29 (1): 3-8. Available at http://www.ncbi.gov/ubmed/166783 28.

- Calzolan, A.,\& Dalgeish, D. (2014): Anatomical and physiological change in pregnancy. Relevant to Anesthesia, World Anesthesia Tutorial of. the Week, www. Anathesial. UK.com./world anesthesia

-Fser, D.\& Cooper, M. (2003) :Myles: Text book for midwives, 14thd. ,Churchill livingstone:London, pp. 13, 216-2i9.

-Htesly,J. \& Mcclurej, (2003): Leg cramps and restless legs syndrome during pregnancy. Journal of Midwives \& Women Health, 54(3):211-218.

- Isbir, G.,\& Mete, S. (2010): Nursing care of nausea and vomiting in
Pregnancy. .Roy Adaptation Model, ,Nursing Science Quarterly; 23(2) :148 155.

-Jewell, D.,(2002):Nausea and vomiting in early pregnancy .Clin Evid 7:1277-83.

9-Jewell D.\& Young G.((2000): Intervention for treating constipation in pregnancy . Clin Evid, 7 :1277-83 .

- Jewell, D.J. Young, G. (2001): Intervention for treating constipation in pregnancy. Cochrane Database Syst Rev CD001142,http//www.ncbinlm.goy/pub med/11405974.

- Klossner, J., \& Hatfield, N. (2010): Introductory maternity \& pediatric nursing .2 nd ed. pp145-151. Wolters Kluwer Lippincott Williams \&Wilkin Philadelphia London .

-- Lowdermilk, D. \& Perry, T. (2007): Maternity \& women health care, 9 th ed. Mosby Company, China, pp380,381 .

--Lowdermilk, D. Berry,S. Cashion K. (2010): Maternity nursing

$10^{\text {th }}$ ed. Anatomy and physiology of of pregnancy ,Mosby Elsevier: Philadelphia pp.190,273 .

--Nancy, J. Karen, B. Megan, Philpottes, P. \& david, I. (2009): A nurse \& Drivid quality improvement program to improve prenatal outcomes. Journal of prenatal \& Neonatal Nursing : July/ September, 24( 1) :250.

--Ngenda G., Langer, A., Kunchaisit , C., Romero,M., Rojas, G., Al-Osimy, M .,et al. ( 2003) :Womens ' opinions on antenatal in Brazilan Southeast : a clinical qualitive study in cuba, Thailand Saudi Arabia and Argntina, BMC. Public Health .3(1):17.

--Orshan S. (2008) :Maternity ,Newborn \&Women's Health Nursing, 
$1^{\text {st }}$ ed., Chapter 13: High risk pregnancy ,Pp,476-480 ,Lippincott Wiliams\&Wilkin,NewYork.

- Pennick, V.E.\& Young G.(2007) : Intervention for preventing and Young treating pelvic Cochrane Database Sys Rev , Apr.

,,(2):CDOO1139.Available at :htt://www.nebi.nih gov/pumed/1744503 .

- Rice.,R. (2006) : Home care nursing practice: Concept and application 4 th ed. mosby Elseriver philadelphia.

- Rosy, M (2010). A study to Assess the knowledge and practice regarding minor disorders of pregnancy and incidence among the mothers who attend OPD In selected hospitals,,Rajiv Gandhi University of health Sciences Bangalore

Karnataka, ,A.E \& C.S Pavan College of Nursing , Kolar

- Quinla, J D. Hill DA.,(2003):Nausea and vomiting of pregnancy. .Am Fam Physican:68:121.

- Smith, S.A. Michel Y., (2006): A pilot study on the effect of aquatic excerises on discomforts of pregnancy .J Obstet. Gynecol Nurses, ;35: 315-323. 